\title{
Estudio secuencial de la interacción sociocognitiva durante la resolución de problemas lógicos
}

\section{Sequential study of the socio-cognitive interaction in logical problem solving}

\author{
Mariano Castellaro ${ }^{1} \underline{O R C I D}$, Nadia Soledad Peralta ${ }^{2} \underline{O R C I D}$, Juan Manuel Curcio ${ }^{3} \underline{O R C I D}$ \\ Consejo Nacional de Investigaciones Científicas y Técnicas (CONICET) \\ Instituto Rosario de Investigaciones en Ciencias de la Educación (IRICE)
}

Universidad Nacional de Rosario (UNR)

Argentina

Fecha correspondencia:

Recibido: marzo 29 de 2019.

Aceptado: septiembre 9 de 2019.

Forma de citar:

Castellaro, M., Peralta, N. S., \& Curcio, J.M. (2020). Estudio secuencial de la interacción sociocognitiva durante la resolución de problemas lógicos. Rev. CES PSico, 13(1), 1-17.

\section{Open access \\ (c) Copyright \\ Licencia creative commons \\ Ética de publicaciones \\ Revisión por pares \\ Gestión por Open Journal System \\ DOl: http://dx.doi.org/10.21615/ \\ cesp.13.1.1 \\ ISSN: 2011-3080}

Sobre los autores:

1. Doctor en Psicología. Psicólogo. Investigador Consejo Nacional de Investigaciones Científicas y Técnicas (CONICET, Argentina), en el Instituto

Comparte

\section{Resumen}

El objetivo del presente estudio fue analizar, desde una perspectiva secuencial, la interacción sociocognitiva durante la resolución colaborativa de problemas lógicos, en díadas de estudiantes de quinto y sexto grado de educación primaria, con composiciones sociocognitivas asimétricas y simétricas. Se trató de un estudio cuasi-experimental de casos, de dos fases: la primera consistió en la resolución individual de ítems lógicos, para evaluar el nivel de competencia específica inicial de cada sujeto. Con base en dicho criterio, se conformaron díadas asimétricas (un compañero de alta competencia con un par de baja competencia) y simétricas (ambos compañeros de baja competencia), que resolvieron la tarea de manera colaborativa. La interacción sociocognitiva fue codificada por un sistema de categorías adaptado. Se realizó un análisis secuencial de la interacción, es decir, de probabilidades de transición entre códigos (eventos); esto se dio al interior de cada condición (asimétrica y simétrica), para detectar patrones secuenciales diferenciales. Los resultados indican patrones de interacción diferentes según la composición de la díada: en las díadas asimétricas, la posibilidad de establecer secuencias de co-construcción de conocimiento depende principalmente de la intervención inicial emitida por el sujeto más competente; en cambio, en las díadas simétricas se constataron niveles altos de alternancia de la participación por ambos compañeros durante la secuencia de interacción. Se ratifica la hipótesis de la influencia de la composición sociocognitiva de la díada sobre la interacción, pero con aporte de considerar a ésta desde una perspectiva secuencial y diacrónica.

Palabras clave: Interacción Sociocognitva, Desarrollo Cognitivo, Aprendizaje Colaborativo, Colaboración entre Pares, Resolución de Problemas, Análisis Secuencial.

\section{Abstract}

This study aims at analyzing the socio-cognitive interaction during the collaborative resolution of logical problems, from a sequential perspective. It is focused on dyads of fifth and sixth graders, with asymmetric and symmetric 
Rosario de Investigaciones en Ciencias de la Educación (IRICE). Docente Facultad de Psicología de la Universidad Nacional de Rosario (UNR, Argentina).

2. Dra. en Psicología.

Psicóloga. Investigadora Consejo Nacional de Investigaciones Científicas y Técnicas (CONICET, Argentina), en el Instituto Rosario de Investigaciones en Ciencias de la Educación (IRICE). Docente Facultad de Psicología de la Universidad Nacional de Rosario (UNR, Argentina).

3. Estudiante Psicología. Facultad de Psicología de la Universidad Nacional de Rosario (UNR, Argentina). Adscripto de iniciación científica en el Instituto Rosario de Investigaciones en Ciencias de la Educación (IRICE), dependiente del Consejo Nacional de Investigaciones Científicas y Técnicas (CONICET, Argentina). socio-cognitive compositions. The design was a quasi-experimental case study with two phases: the first was an individual resolution of logical items to evaluate the initial specific competence level of each subject. Then, it was made up asymmetrical dyads (a high-competence partner with a pair of low competence) and symmetrical (both low-competence partners), which solved the task collaboratively. The socio-cognitive interaction was codified by a system of adapted categories. A sequential analysis of the interaction was performed (analysis of probabilities of transition between codes or events). This was done in relation to each condition (asymmetric and symmetric), to detect differential sequential patterns. The results indicate different interaction patterns depending on the composition of the dyad: asymmetric dyads showed that the possibility of establishing co-construction knowledge sequences depends mainly on the initial intervention issued by the most competent subject; symmetric dyads showed high levels of alternation referred to participation issued by both partners during the interaction sequence. The hypothesis that the influence of the socio-cognitive composition of the dyad on the interaction is ratified, but it is considered from a sequential diachronic perspective.

Keywords: Socio-cognitive Interaction, Cognitive Development, Collaborative Learning, Peer Collaboration, Problem Solving, Sequential Analysis.

\section{Introducción}

El estudio de la relación entre interacción social y cambio cognitivo, sostenido desde perspectivas neopiagetianas y neovygotskianas, lleva varias décadas. Dentro de ese marco, los trabajos pioneros de Doise (1986) y de Perret Clermont, Perret y Bell (1991) han insistido en la necesidad de considerar los procesos involucrados en la construcción social del conocimiento. Hasta ese momento, las investigaciones se enfocaban principalmente en el resultado derivado de la interacción, o sea, sus efectos cognitivos a nivel individual (Peralta \& Castellaro, 2018). De esta manera, ambos trabajos constituyeron el punto de partida de una nueva generación de estudios que propone un cambio fundamental en el foco de análisis (Psaltis, Duveen, \& Perret Clermont, 2009). Si bien la relación entre interacción social y cambio cognitivo aún constituye el sentido teórico básico de las investigaciones, una comprensión cabal de la misma implica necesariamente la consideración del proceso de construcción sociocognitiva involucrado.

Siguiendo a Brizuela y Scheuer (2016), un enfoque procesual del cambio cognitivo debe considerar, al menos, tres cuestiones metodológicas. Primero, centrarse en la consideración del flujo continuo de la experiencia (por ejemplo, la secuencia o trayectoria de la interacción) y no únicamente en cortes transversales o imágenes fijas. Segundo, atender al carácter multimodal, multisensorial, social y distribuido de esos procesos. Tercero, considerar la variabilidad interna a cada caso y/o sujeto, en complemento con las tendencias generales grupales identificadas. Guevara, van Dijk y van Geert (2016) sostienen una idea similar cuando estudian el proceso de razonamiento científico (noción de equilibrio) en preescolares. En el mismo sentido, Tartas, Perret-Clermont y Baucal (2016) proponen el concepto de microhistoria experimental, como un enfoque que permite la indagación de los procesos de cambio social y cognitivo ocurridos entre las diferentes fases de un estudio, aspecto que generalmente ha sido omitido en la literatura.

El presente trabajo pretende retomar algunos aspectos de esta perspectiva teórico-metodológica, en tanto su foco de interés es la secuencia o trayectoria (momento a momento) de la interacción sociocognitiva. Este enfoque se diferencia y -al mismo tiempo- se complementa con estudios previos (Castellaro \& Roselli, 2018a, 2018b), 
La idea de proceso remite a las transformaciones y cambios ocurridos durante una secuencia de tiempo, referidos a la dinámica interactiva y el avance progresivo hacia una solución cognitiva. Precisamente allí se ubica el eje principal del presente estudio. en los cuales la interacción sociocognitiva fue analizada de una manera transversal, es decir, sin considerar sus fluctuaciones durante la realización de la actividad.

El proceso de co-construcción conjunta de conocimientos puede ser entendido desde dos enfoques conceptuales: como negociación y como colaboración (Castellaro \& Roselli 2015; Mejía Arauz, Rogoff, Dayton, \& Henne-Ochoa, 2018). En el primer caso, se enfatiza el valor de la confrontación entre las perspectivas individuales; en otras palabras, la co-construcción de un campo de significación compartida implica una tensión o conflicto entre las propias posiciones epistémico-sociales de los sujetos que interactúan, cuya resolución exige lograr un consenso con base en el intercambio de argumentos. En el segundo caso (colaboración), se enfatiza el carácter de complementariedad interpersonal, en tanto la construcción de un campo de significación compartida implica una coordinación y exploración básica a partir del lenguaje.

Más allá de esta diferenciación conceptual, queda claro que el foco de interés no solo está puesto en la respuesta (producto) lograda por dos o más sujetos que realizan conjuntamente una tarea cognitiva, sino especialmente en el proceso que dio lugar a esa solución. La idea de proceso remite a las transformaciones y cambios ocurridos durante una secuencia de tiempo, referidos a la dinámica interactiva y el avance progresivo hacia una solución cognitiva. Precisamente allí se ubica el eje principal del presente estudio.

En general, la literatura sobre interacción sociocognitiva entre pares se ha enfocado en tareas de razonamiento o cognitivas. Así, se ha priorizado en estudios de tareas inspiradas en la psicología genética piagetiana (por ejemplo, Piaget, 1923/2002): rotación de planos (Psaltis, 2011; Zapiti \& Psaltis, 2012), balance entre pesos (Guevara et al., 2016), trasvasamiento de líquido (Psaltis \& Duveen, 2006, 2007) y razonamiento moral (Garton \& Harvey, 2006; Leman \& Duveen, 2003). En general, estas tareas son utilizadas en un momento evolutivo de pasaje de una lógica pre-operacional hacia una lógica operacional, en el sentido piagetiano del término.

Cuando la interacción entre pares es estudiada en niños de mayor edad, o sea, que ya cuentan con una lógica operatoria claramente instalada (incluso con características formales, como ocurre habitualmente hacia finales de la educación primaria), una tarea muy utilizada en las investigaciones fue del tipo matrices progresivas (por ejemplo, Castellaro \& Roselli, 2018a, 2018b; Rojas-Drummond, Mazón, Fernández, \& Wegerif, 2006; Rojas-Drummond, \& Mercer, 2003; Roselli, 2010; Wegerif et al., 2016; Webb \& Treagust, 2006; Yang, 2015). Este formato de tarea activa y posibilita la observación de procesos intersubjetivos de construcción de soluciones lógicas, lo cual justificó su utilización en este trabajo.

El objetivo del estudio fue analizar, desde una perspectiva secuencial o diacrónica, la interacción sociocognitiva durante la resolución colaborativa de problemas lógicos (similares a los planteados en la literatura), en díadas de estudiantes de quinto y sexto grado de educación primaria. De manera específica, se apuntó a identificar secuencias persistentes y recurrentes (patrones) de categorías interactivas y consecutivas en el tiempo. A su vez, se incluye el análisis de la composición sociocognitiva de la díada, es decir, la igualdad o diferencia entre las competencias individuales de los compañeros de trabajo. En trabajos previos (Asterhan, Schwarz, \& Cohen-Eliyahu, 2014; Castellaro \& Roselli, 2018a, 2018b; Fawcett \& Garton, 2005; Schmitz \& Winskel, 2008) se analizaron los efectos de esta variable sobre la interacción sociocognitiva entre pares, pero desde un enfoque centrado en los aspectos transversales o sincrónicos de la actividad. 
En este caso, si bien se analiza la influencia de la composición sociocognitiva de la díada sobre la interacción sociocognitiva, ésta última es considerada según su trayectoria (secuencia). La hipótesis de base (común a esta línea de investigaciones) que fundamenta el presente trabajo, sostiene que, considerando la naturaleza del contexto de actividad (tarea cognitiva), es esperable que la composición sociocognitiva de la díada influya sobre las características de la interacción.

\section{Método}

\section{Diseño}

Se trató de un estudio cuasi-experimental de casos, constituido por dos fases. La primera consistió en la resolución individual de una serie de ítems lógicos, con el propósito de evaluar el tipo de soluciones propuestas y el nivel de competencia específica inicial de cada sujeto. Con base en dicho criterio, posteriormente se conformaron díadas de dos composiciones sociocognitivas diferentes: asimétrica (un compañero de alta competencia con un par de baja competencia) y simétrica (ambos compañeros de baja competencia). En una segunda fase, de carácter colaborativo, cada díada realizó una serie de ítems equivalente a la primera. La interacción sociocognitiva de las díadas constituyó el dato básico para analizar los patrones secuenciales interactivos en las díadas asimétricas y simétricas.

\section{Participantes}

Dieciocho díadas (36 sujetos) de estudiantes de quinto y sexto grado de primaria (edad, $M=11,22 ; S D=0,61$ ), de dos escuelas oficiales de Rosario, Argentina. La selección de los casos fue no probabilística. Solo participaron del estudio aquellos sujetos que contaron con consentimiento informado propio y del adulto responsable. Tampoco participaron casos con diagnóstico profesional de dificultades de aprendizaje y/o trastorno del desarrollo. Del total de díadas, la mitad tuvo una composición sociocognitiva asimétrica (un sujeto de alta competencia y otro de baja competencia) y el resto una composición simétrica (dos compañeros de baja competencia).

\section{Materiales}

La tarea consistió en una serie de diez problemas lógicos del tipo matrices progresivas (Castellaro \& Roselli, 2018a, 2018b). Cada ítem de la serie estaba constituido por un conjunto de figuras (estímulos visuales) ordenados en filas y columnas (tres figuras por fila y tres figuras por columna) que guardaban una relación de sentido lógico entre sí. La última figura que completaba la secuencia estaba ausente. La resolución de cada problema implicaba deducir la relación de sentido lógico que unía a las figuras y proponer, entre un conjunto de ocho opciones de respuesta disponibles, cuál correspondía a la figura correcta. La prueba contaba con dos versiones paralelas, utilizadas en diferentes fases del estudio. La serie "A" se aplicó en la evaluación individual inicial; la serie "B" (paralela) fue realizada en la fase interactiva diádica. Tal como reportan diversos antecedentes (Cfr. Wegerif et al., 2016), la utilización de esta tarea apuntó a la construcción de un dispositivo de activación de procesos colectivos lógicos, con el fin de estudiar la construcción intersubjetiva de soluciones lógicas. En otras palabras, su utilización se alejó del sentido original o fundacional que fue lograr una evaluación psicométrica individual de la inteligencia (Raven, 1991). El paralelismo entre ambas series se testeó en una prueba piloto anterior al estudio propiamente dicho. Individuos de la misma edad y curso resolvieron dos series con mayor número de ítems que las definitivas, contrabalanceadas en el orden de administración. De esta evaluación, se identificaron 10 pares de ítems que, no solo contaban inicialmente con estructuras lógicas similares, sino también con comportamientos resolutorios equivalentes. Esto 
último se determinó registrando la ausencia de diferencias significativas en el grado de acierto y error por parte de los sujetos (acierto=1, error=0; prueba $T$ de Student para muestras relacionadas, $p=$ n.s.).

\section{Procedimiento}

La realización del estudio incluyó el consentimiento informado de las instituciones escolares, de los participantes y de un adulto responsable de éstos. El proyecto se ajustó a las pautas éticas de las normativas fijadas internacionalmente, tales como el Código de Nüremberg y la Declaración de Helskinski, y demás regulaciones concordantes con éstos. Además, fue revisado y aprobado por el Consejo de Ética y Derechos Humanos de un organismo gubernamental argentino.

Pretest individual. Todos los participantes resolvieron la serie lógica "A" de diez ítems (se adicionaron dos ítems previos de ensayo). Así, se distinguieron dos niveles de competencia inicial y general, basado en el total de ítems resueltos correctamente: baja competencia (hasta 5 ítems correctos) y alta competencia (6 o más ítems correctos). A partir de esta evaluación inicial, se conformaron díadas asimétricas (bajo-alto) y simétricas (bajo-bajo), al interior de cada curso escolar. Como criterio complementario, en las díadas asimétricas los sujetos tenían una diferencia de puntaje total de $\geq 4$ y en las simétricas de $\leq 2$.

Fase interactiva. Durante las dos o tres semanas posteriores tuvo lugar la segunda fase del estudio, de carácter interactivo. Cada díada resolvió la serie lógica "B". La consigna sugería a los compañeros de díada dialogar e intercambiar ideas sobre posibles soluciones de cada problema y consensuar una decisión final al respecto. La interacción fue registrada por audio.

\section{Sistema de categorías de interacción}

El punto de partida fue la distinción entre unidad dialógica (o turno conversacional) y unidad cognitiva (Roselli, 2016). Una unidad dialógica consiste en un segmento comunicacional verbal a cargo de un sujeto, que finaliza por la intervención posterior de su compañero o de manera espontánea. En cambio, la noción de unidad cognitiva refiere al elemento cognitivo más simple en el que se puede dividir un segmento comunicacional. De esta manera, podía ocurrir que una unidad dialógica estuviera integrada por una o varias unidades cognitivas (simple o compuesta, respectivamente), aunque en la mayoría de las ocasiones se dio el primer caso. Un ejemplo de unidad dialógica compuesta (por dos unidades cognitivas) podía ser: "Es el 1 (opción 1) porque en el tercero, en la línea de la derecha, siempre se le saca el punto de arriba del medio. ¿Lo podés ver?". La pregunta final ("¿Lo podés ver?") se considera como una unidad cognitiva diferente a la anterior, más allá de formar parte de la misma unidad dialógica o comunicacional. En definitiva, como el eje de análisis fue la interacción orientada a la resolución de una tarea lógica (sociocognitiva), la unidad de referencia fue cada unidad cognitiva.

Posteriormente, cada unidad cognitiva fue codificada a partir de un sistema categorial anterior (Castellaro \& Roselli, 2018b), el cual tuvo algunas adecuaciones en función de los objetivos del presente estudio.

- Afirmación cognitiva justificada [AJ]: intervención en la cual se intenta justificar o fundamentar (de manera correcta o incorrecta) una idea relativa a la solución de la tarea (no constituye una respuesta a una pregunta inmediatamente anterior). Por ejemplo: "Puede ser el 7 (opción de respuesta) porque acá tienen dos círculos; el A tiene dos círculos, el B tiene uno y el C no tiene nada". 
- Afirmación cognitiva no justificada [ANJ]: intervención en la cual se expone una idea relativa a la solución de la tarea de manera directa, es decir, sin un intento de justificación o fundamentación (puede ser correcta o incorrecta; no constituye una respuesta a una pregunta inmediatamente anterior). Por ejemplo: "La 2 (opción de respuesta), para mí es la 2".

- Afirmación cognitiva procedimental [AP]: intervención en la cual se propone una acción determinada que pueda contribuir a la construcción de y/o demostrar al compañero una idea para la solución de la tarea. Por ejemplo: "Esto es así, mirá" (luego el sujeto desarrolla una idea).

- Pregunta cognitiva de requerimiento de opinión [PO]: intervención dirigida al compañero consultando una idea para la solución del problema, acuerdo o desacuerdo con una idea propia, o cuestionando alguna propuesta previa. Ejemplo 1: “¿Cuál otra (opción de respuesta) podría ser?" (un sujeto preguntando a su compañero). Ejemplo 2: “'Te parece poner la 2 (opción de respuesta)?". Ejemplo 3: Frente a la afirmación "Acá me parece que va el 5 (opción de respuesta)", el sujeto responde: "¿el 5?" (luego de eso, el primer sujeto dice "Sí").

- Pregunta cognitiva de demostración [PD]: interrogación al compañero destinada a presentarle, desarrollarle o ayudarle a comprender una idea o solución al problema. Por ejemplo, “Ves que acá se va formando así? ¿Ves?"

- Respuesta cognitiva argumentada [RA]: intervención que constituye una respuesta a una pregunta inmediatamente anterior en la cual se intenta justificar o fundamentar (de manera correcta o incorrecta) una idea relativa a la solución de la tarea. Por ejemplo, ante la pregunta del compañero (“¿El 7? (opción de respuesta) ¿Seguro?), el sujeto responde: "Sí, porque acá hay 4 (puntos en la figura), 3 (puntos en la figura) y 2 (puntos en la figura)".

- Respuesta cognitiva no argumentada [RNA]: intervención que constituye una respuesta a una pregunta inmediatamente anterior en la cual se expone una idea relativa a la solución de la tarea de manera directa, es decir, sin un intento de justificación o fundamentación (puede ser correcta o incorrecta). Por ejemplo, ante la pregunta del compañero (“¿Cuál otra (opción de respuesta) podría ser?"), el sujeto responde: "Podría ser el 1 o el 5".

- Mensaje no-cognitivo [nc]: intervención vinculada con aspectos organizativos o ajenos a la tarea, no relacionada directamente con la resolución de la misma. Por ejemplo, ante una situación de dificultad frente a la tarea, el sujeto plantea: "Se me complicó, no sé cuál iría acá".

La codificación del corpus total de información estuvo a cargo del primer autor. Con el fin de establecer una confiabilidad básica de dicha codificación, otros dos sujetos (la segunda autora y un asistente de investigación) revisaron una parte del material codificado, ratificando la coincidencia de criterio en la mayoría de las unidades codificadas. Las codificaciones no coincidentes fueron discutidas y resueltas por consenso entre las partes.

\section{Análisis secuencial de la interacción}

El análisis de los códigos (eventos) se realizó sobre ítems puntuales (dos por cada díada), elegidos intencionalmente porque reproducían la asimetría o simetría inicialmente 
detectada en cada díada. Así, en las díadas asimétricas, los ítems seleccionados como prototípicos habían sido resueltos correctamente por el sujeto de mayor competencia general e incorrectamente por el sujeto de menor competencia general; en las díadas simétricas, los ítems habían sido resueltos incorrectamente por ambos sujetos. Esta decisión tuvo su fundamento en la necesidad de analizar particularmente situaciones prototípicas de asimetría o simetría cognitiva, es decir, ítems en los cuales se replique a nivel específico la composición sociocognitiva general de la díada. Vale aclarar que los dos ítems analizados fueron los mismos en la gran mayoría de los casos.

El análisis secuencial de la interacción, al interior de los ítems seleccionados, consistió en el estudio de probabilidades de transición entre los códigos que componían dicha interacción (Bakeman \& Gottman, 1989). Esto se dio de manera separada al interior de las díadas asimétricas, por un lado, y de las simétricas, por el otro. El propósito fue diferenciar patrones secuenciales en cada composición sociocognitiva, es decir, transiciones recurrentes o inhibidas entre códigos consecutivos. Se utilizó el Software GSEQ 5.0 (Bakeman \& Quera, 1996, 2011), diseñado específicamente para este tipo de análisis. El término probabilidad de transición refiere a la posibilidad de que un evento dado, llamado criterio (por ejemplo, un tipo de conducta determinada) se asocie significativamente o no con otro evento que lo sucede en el tiempo, llamado meta. Para determinar la asociación entre ambos códigos, se construye una tabla de contingencia, cuyas filas contienen todos los códigos considerados como criterio (antecedentes) y cuyas columnas contienen los mismos códigos, pero considerados como meta, es decir, inmediatamente posteriores en el tiempo (Guevara et al., 2016). Por lo tanto, cada celda indica la frecuencia con que un evento (fila, criterio) fue sucedido inmediatamente por otro (columna, meta). Luego, se compara la frecuencia observada de cada celda con su frecuencia esperada por azar; dicha diferencia es transformada a un valor $Z$ (ajuste residual), a su vez asociado con un valor $p$. En este caso, los valores $Z$ superiores a 1,96 (positivo o negativo) se consideraron como transiciones significativas entre dos códigos $(p<0,05)$. El signo positivo o negativo de un valor residual sugiere una transición activada o inhibida, es decir, una sucesión entre dos códigos significativamente mayor (más presente) o menor (más ausente) a la esperable por azar (Belza, Herrán, \& Anguera, 2019).

Como se anotó anteriormente, cada unidad cognitiva (ocurrida durante la interacción) recibió un código específico (Cfr. sistema categorial presentado) y fue considerada como un evento (Anguera, 1997; Anguera, Blanco, Losada, \& Portell, 2018). De esta manera, la interacción de cada díada constituyó una secuencia de eventos (códigos). A cada evento codificado se le agregó el valor 1 o 2, para especificar cuál sujeto de la díada lo había emitido: en las díadas asimétricas, el sujeto 1 y 2 fue el de mayor y menor competencia, respectivamente; en las díadas simétricas, como ambos sujetos contaban con baja competencia, la asignación del valor 1 o 2 a cada uno se dio por azar.

En total, las díadas asimétricas registraron 294 eventos y las simétricas 250 . Debido a la naturaleza de los datos (cantidad de códigos, cantidad de eventos, posibilidad de repetición de un mismo código), el foco del análisis de probabilidades de transición estuvo puesto en el retardo 1 (Bakeman \& Gottman, 1989), es decir, en la transición entre el código criterio (también llamado retardo 0) y el código que inmediatamente le sucedía $(+1)$ en la secuencia.

Pero también se consideraron asociaciones entre el código criterio y retardos posteriores, es decir, entre el primero y códigos posteriores en el tiempo, pero con un evento intermedio (retardo +2 ), dos eventos intermedios (retardo +3 ) y tres even- 
tos intermedios (retardo +4). Si los datos mostraban relaciones entre un evento criterio dado y códigos meta en los diferentes retardos (por ejemplo, en $+1,+2,+3$ $y+4)$, ello habilitó a postular una secuencia compleja de eventos. Pero, siguiendo el criterio de Bakeman y Gottman (1989), esta secuencia compleja era aceptada si las relaciones entre los mismos pares de códigos también se cumplían en los retardos anteriores. Por ejemplo, ante una secuencia sugerida de cuatro eventos (con A como evento criterio, B en el retardo 1, C en el retardo 2 y D en el retardo 3), ésta debía ratificarse comprobando la significación de $B$ como evento criterio, $C$ en el retardo 1 y $\mathrm{D}$ en el retardo 2, así como la significación de $\mathrm{C}$ como evento criterio con $\mathrm{D}$ en el retardo 1. Este análisis de retardos permitió explorar y sugerir algunas secuencias particulares más extensas, con las precauciones metodológicas del caso. El análisis secuencial de las díadas se cerró con un análisis hermenéutico de una díada asimétrica y una simétrica, a los fines de ilustrar y profundizar en las tendencias generales detectadas.

\section{Resultados}

\section{Análisis secuencial de las díadas asimétricas}

La Tabla 1 presenta los valores de transición entre códigos dados (criterio) y códigos subsecuentes (meta) en el retardo 1. Complementariamente, la Figura 1 sintetiza los pares de códigos con transiciones significativas desde cada código considerado como evento criterio y los códigos sucesivos en los retardos $+1,+2,+3$ y +4 .

Tabla 1. Ajustes residuales (puntajes Z) significativos* de transición entre códigos (retardo 1), en las díadas asimétricas

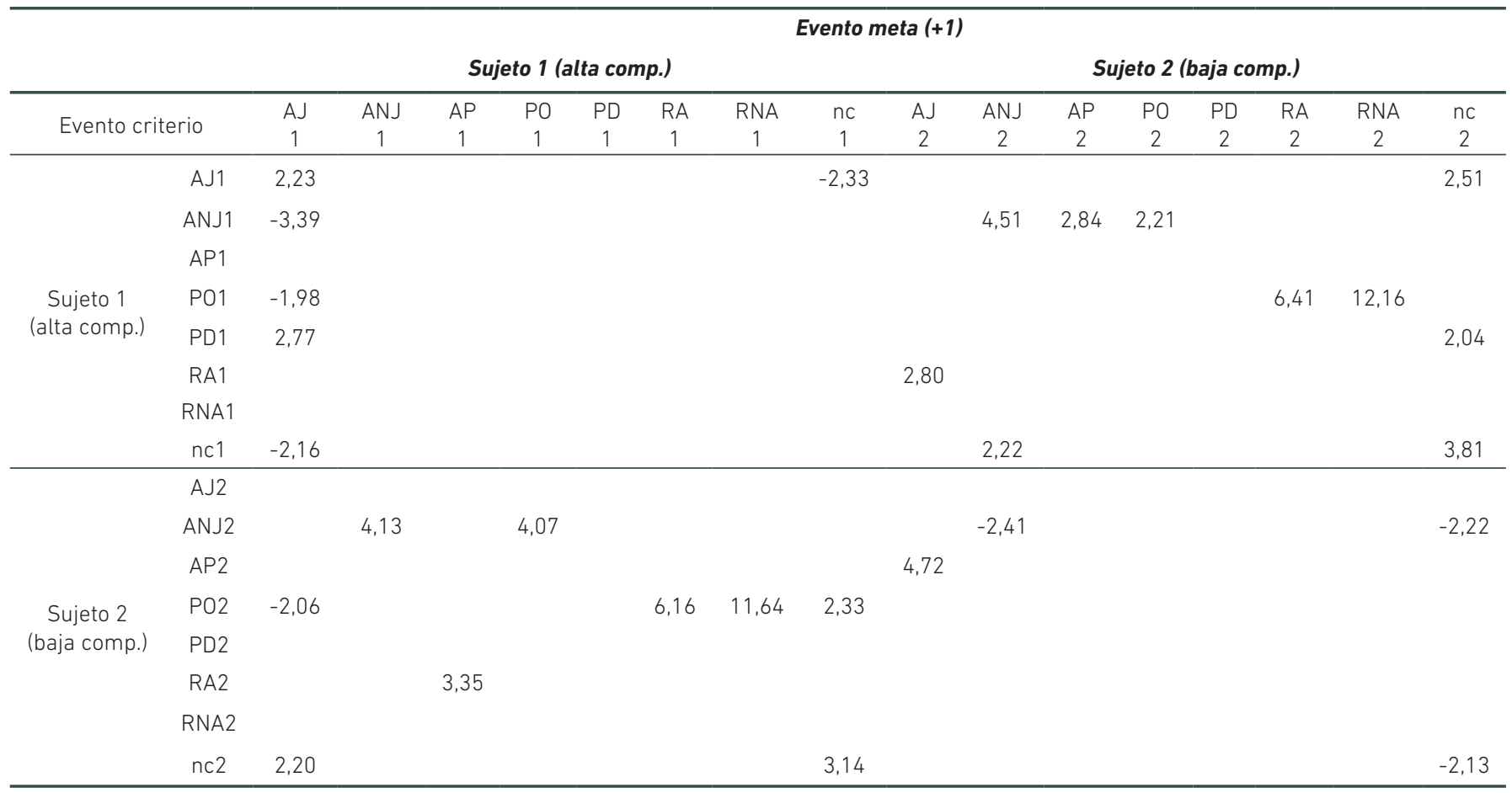

${ }^{*} Z \geq+1,96$ o $Z \leq-1,96 ; p<0,05$. 


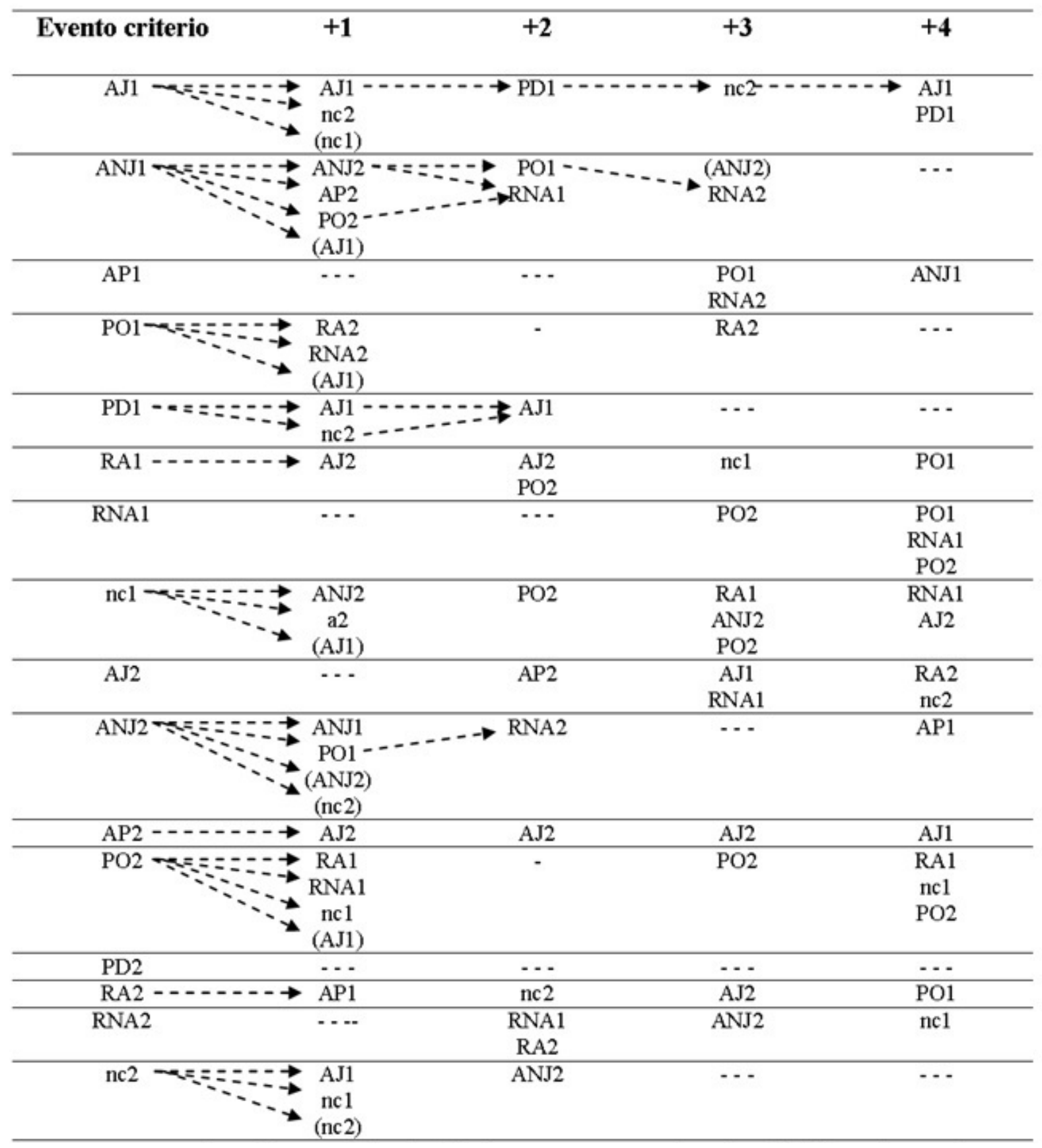

Figura 1. Secuencias de evento identificadas (de 1 a 4 retardos), en díadas asimétricas

Nota: Se presentan los códigos asociados significativamente con un código criterio inicial, en los retardos 1 a $4(Z \geq+1,96 \circ Z \leq-1,96)$. Las flechas indican la formación de una secuencia de evento ratificada.

En las díadas asimétricas, si el evento criterio es una afirmación justificada, generalmente está emitida por el sujeto de mayor competencia. Esto puede ser continuado $(+1)$ de dos maneras: (a) por un aporte no cognitivo del compañero de baja competencia, lo cual concluye el patrón detectado; (b) el sujeto más competente reitera una nueva afirmación justificada, lo cual es continuado (+2) por una pregunta de demostración (+2) emitida por el mismo. Luego de ello surge la devolución del sujeto menos competente (+3), aunque ésta es de carácter no cognitivo. El ciclo concluye 
(+4) por una nueva afirmación justificada o una nueva pregunta de demostración del sujeto más competente, que podría interpretarse como reafirmación de la propuesta inicial.

En cambio, si el evento criterio es una afirmación no justificada, ésta puede ser emitida tanto por el sujeto de mayor competencia como por el de menor competencia. Además, el desenlace posterior también es bastante similar entre ambas situaciones, puesto que en el retardo 1 aparece una retroalimentación cognitiva del compañero, que puede ser una afirmación no justificada o una pregunta de opinión. Esto puede ser seguido (en +2) por una respuesta cognitiva no argumentada de quién emitió el evento inicial o por una pregunta de opinión (únicamente en el caso de que el sujeto de mayor competencia haya iniciado el ciclo). Una última diferencia también se da en el retardo (+3), si el iniciador de la secuencia es el sujeto más competente. En este retardo, es probable una nueva retroalimentación cognitiva no justificada del sujeto de menor competencia.

Respecto a las preguntas de opinión como criterio, más allá de cuál sujeto las emita, éstas son continuadas por una respuesta cognitiva (argumentada o no argumentada) por parte del compañero $(+1)$. Vale recordar que la pregunta de opinión implica que el sujeto convoque al alter en la construcción de un consenso o decisión conjunta. En este sentido, se puede observar con claridad cómo la pregunta al compañero predispone a la construcción conjunta, a diferencia de lo que ocurre con las afirmaciones que, si bien pueden darse en un marco de elaboración compartida, proponen directamente una idea sin requerir necesariamente la mediación previa del compañero. Además, la pregunta de opinión "amortigua" la distancia sociocognitiva entre el sujeto más competente y el menos competente, lo cual no se da en las afirmaciones, especialmente las justificadas.

En el caso de las preguntas de demostración como evento criterio, generalmente están a cargo del sujeto más competente, pudiendo ser continuadas $(+1)$ por una afirmación justificada del mismo. También puede continuarse $(+1)$ por la intervención del compañero de menor competencia, pero ésta es de carácter no cognitivo. Por último, en cuanto a las intervenciones no cognitivas como evento criterio, pueden darse dos situaciones posteriores $(+1)$, independientemente del sujeto que las emita: (a) ser continuadas por una intervención no cognitiva del compañero; (b) ser continuadas por una intervención cognitiva del compañero, aunque ésta es justificada en el caso del sujeto más competente y no justificada en el caso del menos competente.

Como ilustración de la condición asimétrica, la Figura 2 muestra la interacción de la díada de K. y S. (baja y alta competencia, respectivamente).

En el fragmento se observa una alternancia comunicacional fluida en gran parte de la interacción. A pesar de esto, esos ciclos de interacción son asimétricos en función del tipo de aportes efectuados por cada sujeto: S. (de alta competencia) emite mayormente intervenciones cognitivas justificadas (AJ) y no justificadas (ANJ), junto a preguntas de requerimiento de opinión (PO) y de demostración (PD). Por su parte, K. (de baja competencia) retroalimenta dichas intervenciones mayormente con aportes no cognitivos (nc), aunque también lo logre -en algunas ocasiones- a través de aportes cognitivos (AJ y ANJ). En este sentido, también vale destacar las respuestas argumentadas (RA) y no argumentadas (RNA) de K., como un indicador de coordinación con S., principal responsable de las preguntas cognitivas durante la tarea. 
Pág 11

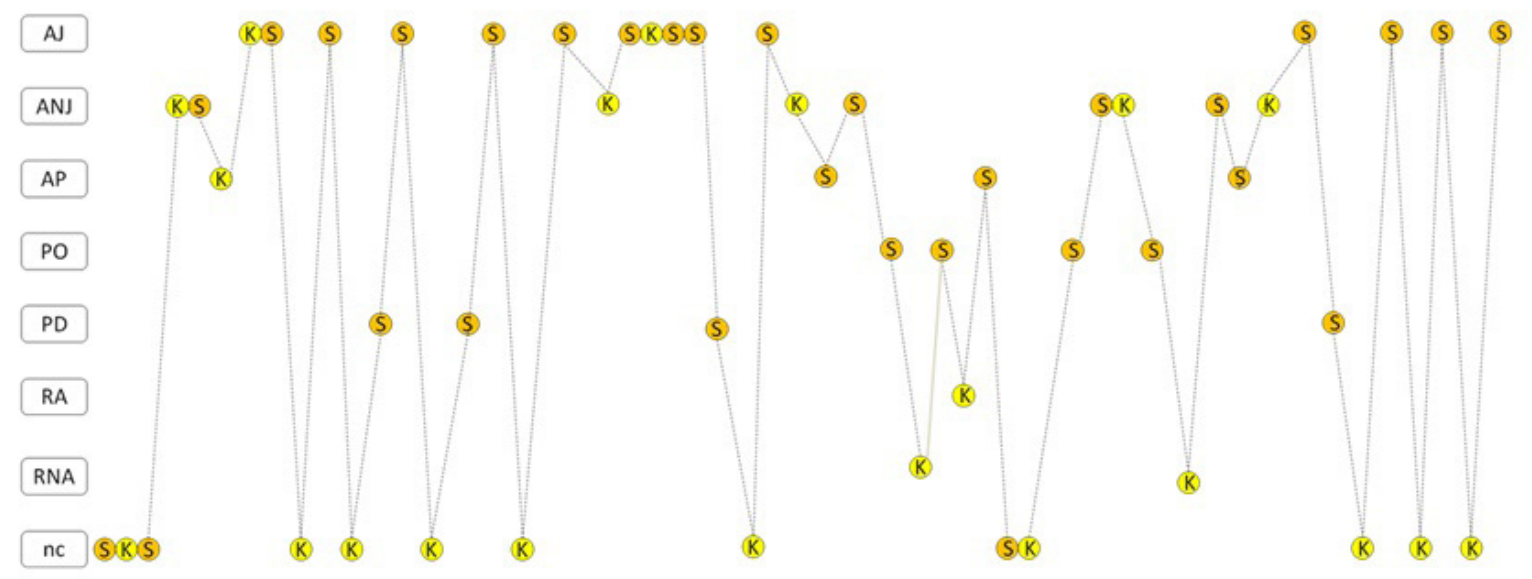

Figura 2. Interacción de díada asimétrica: K (baja competencia) y S (alta competencia).

\section{Análisis secuencial de las díadas simétricas}

Por su parte, con relación a las díadas simétricas, se sigue un esquema similar al utilizado en el análisis secuencial de las díadas asimétricas. La Tabla 2 y Figura 3 presentan los resultados correspondientes a la condición simétrica.

Tabla 2. Ajustes residuales (puntajes Z) significativos* de transición entre códigos (retardo 1), en díadas simétricas

\begin{tabular}{|c|c|c|c|c|c|c|c|c|c|c|c|c|c|c|c|c|c|}
\hline & & \multicolumn{16}{|c|}{ Evento meta (+1) } \\
\hline & & \multicolumn{8}{|c|}{ Sujeto 1 (baja comp) } & \multicolumn{8}{|c|}{ Sujeto 2 (baja comp) } \\
\hline \multicolumn{2}{|c|}{ Evento criterio } & AJ & ANJ & AP & $\mathrm{PO}$ & $\mathrm{PD}$ & RA & RNA & $\mathrm{nc}$ & AJ & ANJ & $\mathrm{AP}$ & $\mathrm{PO}$ & $\mathrm{PD}$ & RA & RNA & $\mathrm{nc}$ \\
\hline \multirow{6}{*}{$\begin{array}{l}\text { Sujeto } \\
1 \text { (baja } \\
\text { comp) }\end{array}$} & ANJ1 & & $-2,94$ & & & & & & & & 3,74 & & 3,89 & & & & \\
\hline & AP1 & & & & & & & & & & & 2,85 & & & & & \\
\hline & P01 & & & & & & & & & & & & & & 10,04 & & \\
\hline & RA1 & & & & & 10,75 & & & & & & & & & & & \\
\hline & RNA1 & & & 3,17 & & & & & & & & 2,48 & & & & & \\
\hline & nc1 & & & & & & & & & & & & & & & & 2,13 \\
\hline \multirow{4}{*}{$\begin{array}{l}\text { Sujeto } \\
2 \text { (baja } \\
\text { comp) }\end{array}$} & AJ2 & & & & & & & & & 2,04 & & & & & & & \\
\hline & ANJ2 & 2,61 & 3,06 & & & & & & & & & & & & & & \\
\hline & RNA2 & & & & & & & & & & & & & & & & \\
\hline & nc2 & & & & 2,69 & & 3,26 & & 3,56 & & & & & & & & \\
\hline
\end{tabular}

$* Z \geq+1,96 \circ Z \leq-1,96 ; p<0,05$ 


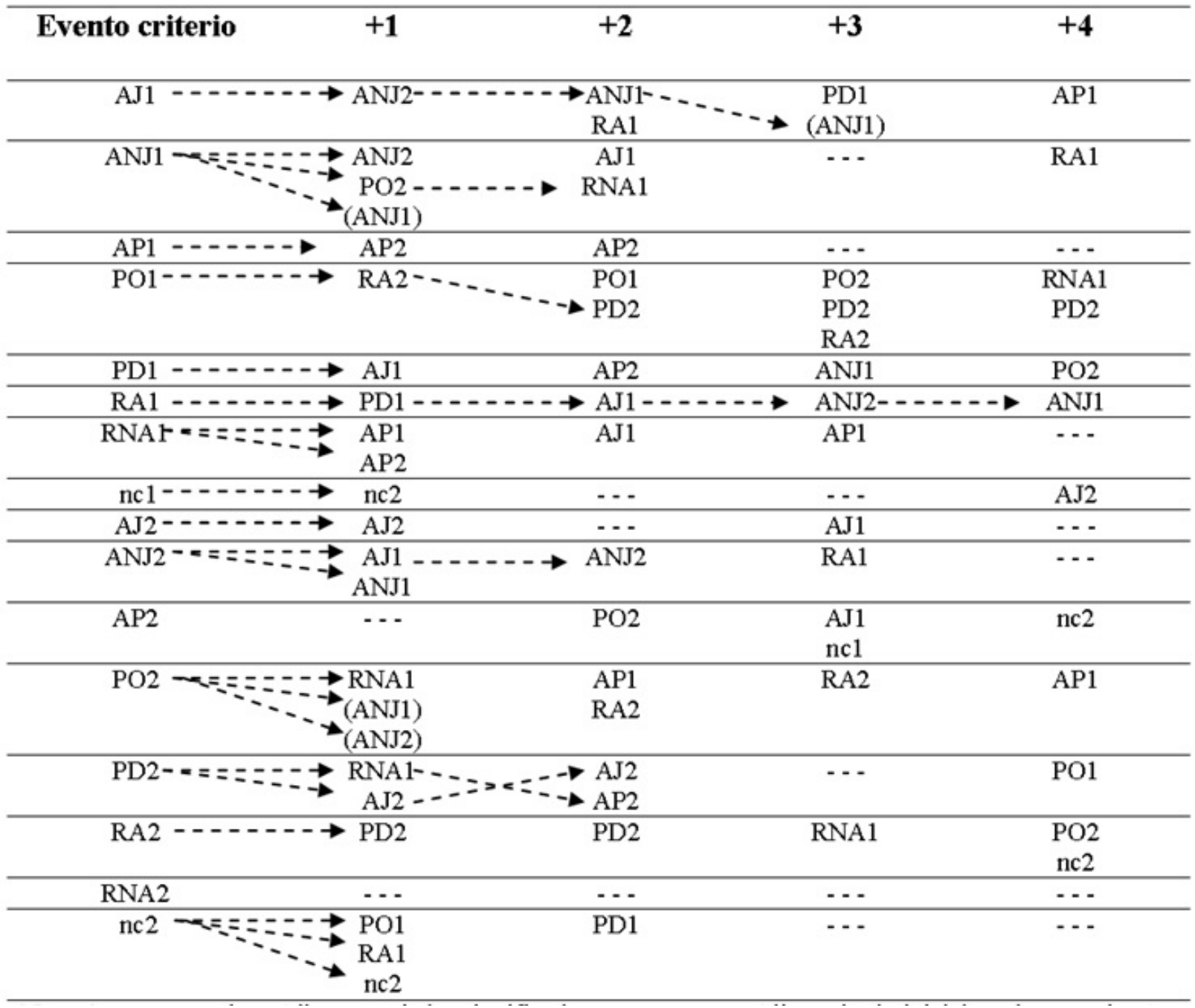

Figura 3. Secuencias de evento identificadas (de 1 a 4 retardos), en díadas simétricas

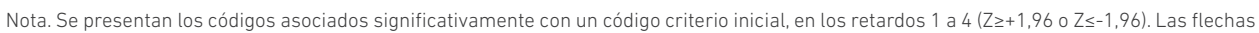
indican la formación de una secuencia de evento continuada.

La mayoría de las probabilidades de transición significativas corresponden a pares de códigos aportados, cada uno, por uno de los compañeros. Esto implica una mayor alternancia comunicacional que en las díadas asimétricas. Cuando el evento criterio es una afirmación justificada, son esperables dos desenlaces en el retardo 1: (a) una retroalimentación cognitiva no justificada del compañero; (b) una nueva afirmación justificada por parte del mismo sujeto (continuación o complemento de la idea previa emitida por sí mismo). Una tendencia similar se observa cuando el evento criterio es una intervención no justificada: en el retardo 1 (+1), el otro sujeto aporta una nueva intervención, justificada o no. Además, esto puede continuarse (+2) por una retroalimentación cognitiva no justificada del sujeto iniciador de la secuencia. También puede ocurrir que este feedback comunicacional esté constituido por una pregunta de opinión en el retardo 1 (del segundo sujeto) y la posterior (+2) respuesta no justificada del sujeto emisor del evento criterio.

Las preguntas cognitivas de requerimiento de opinión (como criterio) estuvieron seguidas (+1) por respuestas argumentadas y no argumentadas del compañero. Esto último se ratifica con las transiciones inhibidas (de signo negativo) relativas a las 
afirmaciones cognitivas no justificadas en el mismo retardo +1. Más específicamente, también se observa que, cuando la respuesta del compañero (a la pregunta de requerimiento de opinión) es justificada, éste tiene la tendencia a completarla con una pregunta de demostración (retardo 2).

Respecto a las preguntas de demostración (como evento criterio), es interesante observar su vinculación inmediatamente posterior (+1) con una afirmación cognitiva justificada emitida por el mismo sujeto emisor de la primer pregunta. Esto podría indicar que la pregunta de demostración no es suficiente para generar una devolución por parte del compañero, sino que es necesario ratificarla con una, incluso dos, justificaciones (como se aprecia en el retardo 2). También puede observarse la transición inversa, desde una respuesta justificada como evento criterio y una pregunta de demostración como reforzador y comunicador de la idea inicialmente propuesta y fundamentada.

En cuanto a las respuestas argumentadas (como criterio), son continuadas por una pregunta de demostración emitida por el mismo sujeto responsable de las primeras. Esto podría interpretarse como un intento de continuación o reafirmación de la idea previa, lo cual tiene una valor sociocognitivo importante en tanto no solo se responde a una inquietud del compañero (presente en el retardo 0), sino que esto se continúa (en el retardo 1) por una pregunta dirigida a facilitar la comprensión del mismo. Por último, en cuanto a las intervenciones no cognitivas consideradas como criterio, pueden ser continuadas por otra intervención cognitiva o no cognitiva de su compañero.

La Figura 4 presenta la interacción de F. y J., el caso de una díada seleccionada para ilustrar la condición de simetría.

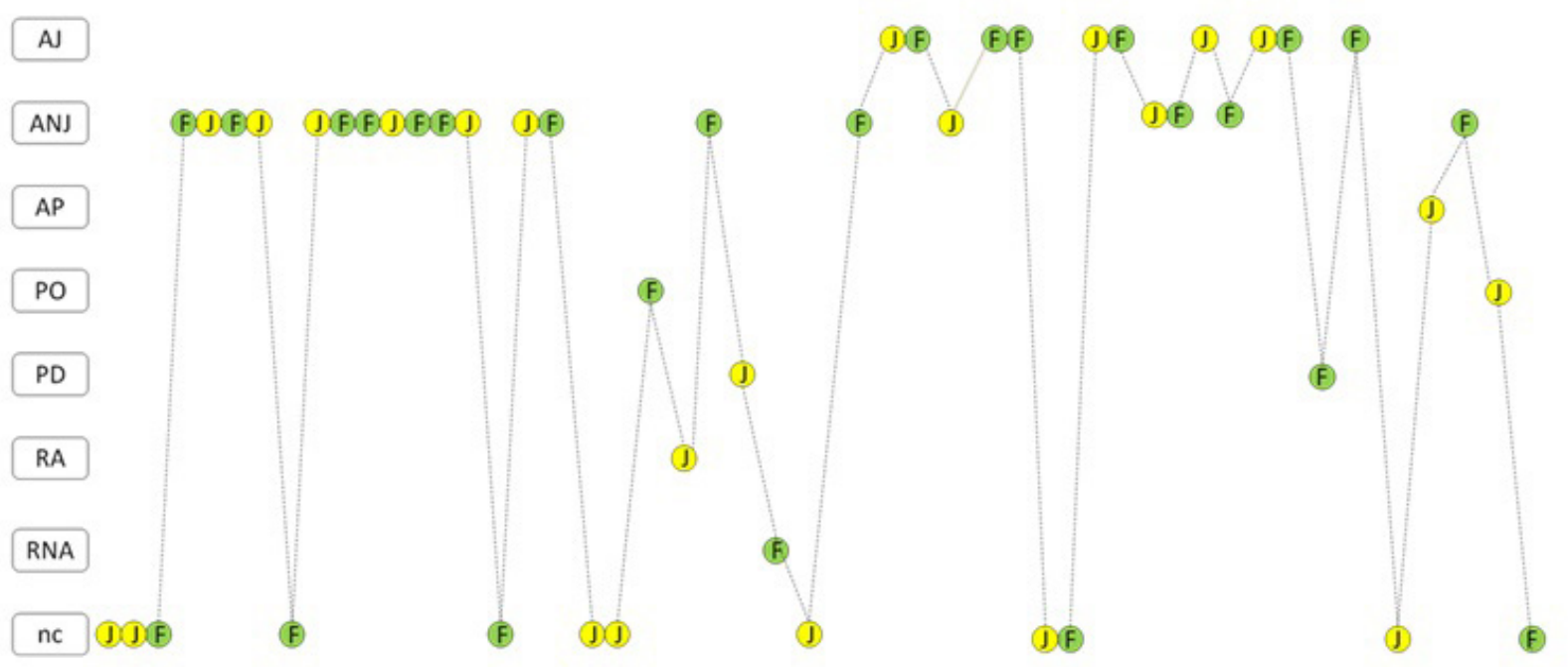

Figura 4. Ejemplo de díada simétrica: F (baja competencia) y J (baja competencia).

De igual forma a lo observado en el caso de K. y S. (díada asimétrica presentada más arriba), en este caso (diada conformada por F. y J.) también existe una alternancia comunicacional. Sin embargo, a diferencia del caso anterior, esto es acompañado por un aporte equitativo en el tipo de unidades cognitivas aportadas. En la gráfica puede observarse una primera secuencia con alternancia de intervenciones cognitivas no justificadas (ANJ), interrumpida por algunos mensajes no cognitivos (nc), también 
Pág 14

La interacción generalmente es iniciada por el sujeto más competente, lo cual es esperable; en segundo lugar, si su participación supone una justificación acabada de la resolución del problema entonces bloquea la participación del compañero; si es solo una respuesta tentativa sin justificaciones, lo habilita. de ambos sujetos. Esta distribución equitativa en los tipos de unidades emitidas se mantiene en una fase intermedia de la interacción, donde ambos compañeros realizan preguntas de requerimiento de opinión (en el caso de F.) y de demostración (en el caso de J.), frente a las cuales se observa una reciprocidad del alter. Luego de este intermedio, la díada propone una nueva secuencia de aportes cognitivos, esta vez incluyendo también aportes justificados (AJ), y con algunos mensajes no cognitivos, de igual forma a la primera parte de la interacción.

\section{Discusión}

El objetivo del estudio fue analizar, desde una perspectiva secuencial, la interacción sociocognitiva durante la resolución colaborativa de problemas lógicos, en díadas de estudiantes de quinto y sexto grado de educación primaria. A su vez, esto fue analizado en dos tipos de composición sociocognitiva diádica: asimétrica y simétrica.

Los resultados relativos a la influencia de la composición de la díada sobre la interacción sociocognitiva son coherentes y se complementan con los hallazgos de trabajos anteriores (Asterhan et al., 2014; Castellaro \& Roselli, 2018a, 2018b; Fawcett \& Garton, 2005; Schmitz \& Winskel, 2008). En ese sentido, se ratifica la hipótesis de que, en el marco de una tarea cognitiva, la desigualdad o igualdad entre las competencias específicas de los compañeros de trabajo se traducen en formas interactivas sociocognitivas diferentes entre sí. Pero este estudio permite visualizar a la interacción en un sentido secuencial, es decir, considerando las intervenciones -y quién las emiteque se van sucediendo durante la realización de la tarea, a diferencia de los enfoques tradicionales donde la simetría-asimetría relacional se evalúa en términos de aportes totales individuales.

En el caso de las díadas asimétricas, los hallazgos sugieren que de acuerdo con el modo como se inicia la secuencia de interacción, ésta se desenvuelve de una manera diferencial. Si la interacción es iniciada por el sujeto competente con una afirmación fundamentada no conlleva una devolución cognitiva por parte del compañero de menor competencia; por el contrario, es esperable una participación de este último de carácter no cognitivo. En ese sentido, podría afirmarse que, más allá de la contundencia o claridad de la justificación aportada, se reduce notoriamente la posibilidad de participación específicamente cognitiva del compañero. Incluso, esto perdura aún cuando el sujeto de mayor competencia efectúe nuevas afirmaciones justificadas o preguntas de demostración de la solución propuesta. En cambio, si la interacción se inicia con una afirmación no justificada (propuesta de una solución sin un fundamento explícito) por parte del sujeto más competente, sí parece habilitar a una retroalimentación cognitiva posterior del compañero menos competente. En este caso se pueden proponer dos conclusiones al respecto: en primer lugar, la interacción generalmente es iniciada por el sujeto más competente, lo cual es esperable; en segundo lugar, si su participación supone una justificación acabada de la resolución del problema entonces bloquea la participación del compañero; si es solo una respuesta tentativa sin justificaciones, lo habilita.

Más allá de esta diferencia, se pudo observar que en ninguno de los dos casos la interacción desemboca en una retroalimentación cognitiva fundamentada del sujeto menos competente (situación ideal si se espera que luego de la interacción este último logre realizar una afirmación cognitiva justificada). Sin embargo, en la primera secuencia de interacción (el sujeto competente aporta una afirmación justificada) el desenlace es puramente social; el sujeto más competente otorga la resolución del problema y el otro se limita a aceptarlo (Peralta \& Roselli, 2016). En cambio, en 
la segunda secuencia (el sujeto competente aporta una afirmación sin justificar) el desenlace podría acercarse a lo que en la literatura se entiende como sociocognitivo, dado que habilita el desarrollo de los aspectos interactivos básicos de cualquier diálogo argumentativo; afirmar, preguntar, demostrar, etc. sumando a que el mensaje final nunca es una afirmación no cognitiva. En síntesis, la interacción iniciada por el sujeto de alta competencia con una afirmación no justificada no sólo habilita a la participación del compañero, sino que su desenlace es mucho más beneficioso en términos sociocognitivos. Podría afirmarse que la co-construcción de conocimientos (Castellaro \& Roselli, 2015; Mejía Arauz et al., 2018) se cumpliría en esta segunda secuencia y no en la primera.

Por su parte, en las díadas simétricas se constató una mayor alternancia de la participación que en las díadas asimétricas. La interacción típica se inicia con una afirmación (justificada o no) brindada por cualquiera de los dos sujetos, seguida por el feedback del compañero basado fundamentalmente en otra afirmación, en la mayoría de los casos no justificada. Las preguntas cognitivas de requerimiento de opinión generalmente desencadenan respuestas argumentadas y no argumentadas del compañero, mientras que las preguntas de demostración son seguidas por una afirmación justificada del compañero.

En términos generales, el trabajo representa un aporte al conjunto de investigaciones sobre interacción sociocognitiva, en tanto propone un análisis de la interacción que incluye la dimensión secuencial o longitudinal de la misma. Esto se diferencia de las investigaciones que en general han privilegiado un enfoque transversal, el cual, si bien ha permitido profundizar el conocimiento de los efectos de la interacción colaborativa, omite la consideración de lo que ocurre durante la interacción. En este sentido, la perspectiva aquí adoptada aporta, desde una óptica complementaria, a una comprensión más integral de la interacción sociocognitiva, y abre el camino no solo a estudios sobre cuestiones pendientes de investigación, sino también a una reinterpretación de los datos de estudios anteriores que analizaron la interacción entre pares exclusivamente desde un enfoque transversal o sincrónico.

\section{Referencias}

Anguera, M. T. (1997). Metodología de la Observación en Ciencias Humanas. Madrid: Cátedra.

Anguera, M. T., Blanco, A., Losada, J. L., \& Portell, M. (2018). Pautas para elaborar trabajos que utilizan la metodología observacional. Anuario de Psicología, 48, 9-17. doi: https:// doi.org/10.1016/j.anpsic.2018.02.001

Asterhan, C., Schwarz, B., \& Cohen-Eliyahu, N. (2014). Outcome feedback during collaborative learning: Contingencies between feedback and dyad composition. Learning and Instruction, 34, 1-10. doi: http://dx.doi.org/10.1016/j.learninstruc.2014.07.003

Bakeman, R., \& Gottman, J.M. (1989). Observación de la interacción: introducción al análisis secuencial. Madrid: Morata.

Bakeman, R., \& Quera, V. (1996). Análisis de la interacción. Análisis secuencial con SDIS-GSEQ. Madrid: Rama.

Bakeman, R., \& Quera, V. (2011). Sequential Analysis and Observational Methods for the Behavioral Sciences. Cambridge: Cambridge University Press.

Belza, H., Herrán, E., \& Anguera, M. T. (2019). Early childhood education and cultural learning: systematic observation of the behaviour of a caregiver at the Emmi Pikler nursery school during breakfast. Infancia y Aprendizaje, Journal for the Study of Education and Development, 42(1), 128-178. doi: https://doi.org/10.1080/0 $\underline{2103702.2018 .1553268}$ 
Brizuela, B. M., \& Scheuer. N. (2016). Investigating cognitive change as a dynamic process / Investigar el cambio cognitivo como proceso dinámico. Infancia y Aprendizaje (39)4, 627-660. doi: https://doi.org/10.1080/02103702.2016.1223710

Castellaro, M., \& Roselli, N. (2015). Peer collaboration in children according to age, socioeconomic context and task. European Journal of Psychology of Education, 30(1), 63-80. doi: https://doi.org/10.1007/s10212-014-0228-3

Castellaro, M., \& Roselli, N. (2018a). Interacción sociocognitiva entre pares en situaciones simétricas y asimétricas de competencia epistémica. Revista de Psicología, 36(1), 333-365. doi: https://dx.doi.org/10.18800/psico.201801.011

Castellaro, M., \& Roselli, N. (2018b). Resolución colaborativa de problemas lógicos en condiciones de simetría y asimetría cognitiva. Revista Propósitos y Representaciones, 6(1) (en línea). doi: https://dx.doi.org/10.20511/pyr2018.v6n1.196

Doise, W. (1986). Levels of explanation in social psychology: European monographs in social psychology. Cambridge, London: Cambridge University Press.

Fawcett, L., \& Garton, A. (2005). The effect of peer collaboration on children's problem-solving ability. British Journal of Educational Psychology, 75(2), 157-169.

Garton, A., \& Harvey, R. (2006). Does social sensitivity influence collaborative problem solving in children? A preliminary investigation. The Australian Educational and Developmental Psychologist, 23(2), 5-16. doi: https://doi.org/10.1017/S0816512200028959

Guevara, M., van Dijk, M., \& van Geert, P. (2016). Microdevelopment of peer interactions and scientific reasoning in young children / Microdesarrollo de la interacción entre pares y el razonamiento científico en niños pequeños. Infancia y Aprendizaje, (39)4, 727-771. doi: https://doi.org/10.1080/02103702.2016.1215083

Leman, P., \& Duveen, G, (2003). Gender identity, social influence and children 's conversations. Swiss Journal of Psychology, 62(3), 149-158. doi: http://dx.doi. org/10.1024//1421-0185.62.3.149

Mejía Arauz, R., Rogoff, B., Dayton, A., \& Henne-Ochoa, R. (2018). Collaboration or negotiation: two ways of interacting suggest how shared thinking develops. Current Opinion in Psychology, 23, 117-123. doi: https://doi.org/10.1016/j.copsyc.2018.02.017

Peralta, N. S., \& Castellaro, M. (2018), "Interacción e intersubjetividad: Investigando sus beneficios en el ámbito educativo". En J. Faccendini, P. Martino, M. Sironi y M. Terrádez (Comp.), Caleidoscopio. Prácticas y Clínicas Psi en la Universidad (pp. 247259). Rosario: UNR Editora.

Peralta, N. S., \& Roselli, N. (2016). Conflicto sociocognitivo e intersubjetividad: análisis de las interacciones verbales en situaciones de aprendizaje colaborativo. Psicología, Conocimiento y Sociedad, 6(1), 90-113.

Perret Clermont, A., Perret, J., \& Bell, N. (1991). The social construction of meaning of and cognitive activity in elementary school children. In L. Resnick, J. Levine y Teasley, S. (Eds.), Shared cognition: thinking as social practice (pp. 41-63). Washington DC, USA: American Psychological Association.

Piaget, J. (2002). The language and thought of the child. London, England: Routledge (Original work published in 1923).

Psaltis, C. (2011). The constructive role of gender asymmetry in social interaction: Further evidence. British Journal of Developmental Psychology, 29, 305-312. doi: https://doi.org/10.1111/j.2044-835X.2011.02029.x

Psaltis, C., \& Duveen, G. (2006). Social relations and cognitive development: The influence of conversation type and representations of gender. European Journal of Social Psychology, 36, 407-430. doi: https://doi.org/10.1002/ejsp.308

Psaltis, C., \& Duveen, G. (2007). Conservation and conversation types: Forms of recognition and cognitive development. British Journal of Developmental Psychology, 25, 79-102. doi: https://doi.org/10.1348/026151005X91415 
Psaltis, C., Duveen, G., \& Perret Clermont, A. (2009). The Social and the Psychological: Structure and context in intellectual development. Human Development, 52(5), 291-312. doi: https://doi.org/10.1159/000233261

Raven, J. (1991). Test de matrices progresivas para la medida de la capacidad intelectual (de sujetos de 12 a 65 años). Manual. Buenos Aires: Paidós.

Rojas-Drummond, S., \&y Mercer, N. (2003). Scaffolding the development of effective collaboration and learning. International Journal of Educational Research, 39(1-2), 99-111. doi: https://doi.org/10.1016/S0883-0355(03)00075-2

Rojas-Drummond, S., Mazón, N., Fernández, M., \& Wegerif, R. (2006). Explicit reasoning, creativity and co-construction in primary school children's collaborative activities. Journal of Thinking Skills and Creativity, 1(2), 84-94. doi: https://doi. org/10.1016/j.tsc.2006.06.001

Roselli, N. (2010). Comparación experimental entre tres modalidades de enseñanza mediadas informáticamente. Revista de Investigación Educativa, 28(2), 265-282. http://revistas.um.es/rie/article/view/97981

Roselli, N. (2016). Modalities to collaborate in the social construction of conceptual maps: A comparison between individual and collective productions. American Journal of Educational Research, 5(10), 1058-1064. doi: https://doi.org/10.12691/ education-5-10-7

Schmitz, M., \& Winskel, H. (2008). Towards effective partnerships in a collaborative problem-solving task. British Journal of Educational Psychology, 78, 581-596.

Tartas, V., Perret-Clermont, A. N., \& Baucal, A. (2016). Experimental micro-histories, private speech and a study of children's learning and cognitive development / Microhistorias experimentales, habla privada y un estudio del aprendizaje y el desarrollo cognitivo en los niños. Infancia y Aprendizaje, (39)4, 772-811. doi: https://doi.org/10.1080/02103702.2016.1221055

Webb, P., \& Treagust, D. (2006). Using exploratory talk to enhance problem-solving and reasoning skills in grade-7 science classrooms. Research in Science Education, 36(4), 381-401. doi: https://doi.org/10.1007/s11165-005-9011-4

Wegerif, R., Fujita, T., Doney, J., Pérez Linares, J., Andrews, R., \& Rhyn, C. (2016). Developing and trialing a measure of group thinking. Learning and Instruction, 48, 40-50. doi: https://doi.org/10.1016/j.learninstruc.2016.08.001

Yang, Y. (2015). Lessons learnt from contextualizing a UK teaching thinking program in a conventional Chinese classroom. Thinking Skills and Creativity, 19, 198-209. doi: https://doi.org/10.1016/j.tsc.2015.07.002

Zapiti, A., \& Psaltis, C. (2012). Asymmetries in peer interaction: The effect of social representations of gender and knowledge asymmetry on children's cognitive development. European Journal of Social Psychology, 42, 578-588. doi: https://doi. org/10.1002/ejsp.1885 